\title{
Purification and characterization of a phospholipid-hydrolyzing phosphoesterase produced by Pediococcus acidilactici isolated from Gouda cheese
}

Israel García-Cano, Diana Rocha-Mendoza, Erica Kosmerl, () and Rafael Jiménez-Flores* ()

Department of Food Science and Technology, The Ohio State University, Columbus 43210

\begin{abstract}
Lipolysis occurs during ripening of dairy products as a result of esterase or lipase activity. Lactic acid bacteria $(\mathrm{LAB})$ are considered to be weakly lipolytic bacteria compared with other species. In cheeses with extended ripening periods, lipolytic LAB may have several advantages. Pediococcus acidilactici is a LAB frequently found in fermented dairy products, but no previous reports exist on their production of esterases or lipases. Our interest in the relationship of LAB and enzymatic characterization is due to the multiple reports of the benefits of LAB in the gut microbiome, particularly at the intestinal membrane. Pediococci have been characterized as probiotic and especially active in membrane interactions. The aim of this project was to purify, characterize, and identify the phosphoesterase produced by $P$. acidilactici originally isolated from Gouda cheese and determine its phospholipid (PL) hydrolysis profile, with a focus on increased absorption of these compounds in the human gut. Native zymograms were performed to identify a protein with lipolytic activity in the intracellular fraction of $P$. acidilactici. The enzyme was purified via size-exclusion HPLC, concentrated via ultrafiltration, and identified using sequence analysis in liquid chromatography (LC)-MS/MS. The purified fraction was subjected to biochemical characterization as a function of $\mathrm{pH}$, temperature, ion concentration, hydrolysis of different substrates, and PL. A single protein with a molecular weight of $86 \mathrm{kDa}$ and esterase activity was detected by zymography. Analysis of the LC-MS/MS results identified a putative metallophosphoesterase with a calculated molecular weight of $45.5 \mathrm{kDa}$, suggesting that this protein is active as a homodimer. The pure protein showed an optimal activity between $\mathrm{pH} 8.0$ to 9.0. The optimal temperature for activity was $37^{\circ} \mathrm{C}$, and the enzyme lost $15 \%$ of activity
\end{abstract}

Received November 26, 2019

Accepted January 8, 2020.

*Corresponding author: jimenez-flores.1@osu.edu after incubation at $90^{\circ} \mathrm{C}$ for $1 \mathrm{~h}$. This enzyme showed activity on short-chain fatty acids and exhibited high hydrolysis of phosphatidylinositol. It also hydrolyzed phosphatidylserine, phosphatidylcholine, and sphingomyelin. Phosphatidylethanolamine was hydrolyzed but with less efficiency. The characteristics and lipolytic actions exerted by this protein obtained from LAB hold promise for a potential strain of esterase or lipase that may exert human health benefits through increased digestibility and absorption of nutrients found in dairy products.

Key words: phospholipid, Pediococcus acidilactici, phosphoesterase, Gouda cheese

\section{INTRODUCTION}

Gouda is a semi-hard cheese originating from Holland. Its characteristics depend on the composition, dynamics, and interactions of the cheese microbiota. During cheese manufacturing, the initiation of the fermentation process begins with the inoculation of a starter culture to the milk. Some factors, such as the type of milk and starter culture, have been recognized as major determinants of the cheese microbiota. Lactic acid bacteria (LAB) are the principal microbes responsible for fermentation, due to their metabolic properties that significantly contribute to flavor, texture, nutritional value, and microbial safety (Van Hoorde et al., 2010). In many dairy products, such as cheese, the microbiota is composed of starter and nonstarter LAB. Starter LAB are principally involved in acid production, whereas nonstarter LAB dominate the microbiota during the ripening process, contributing to the development of the cheese's final characteristics (Settanni and Moschetti, 2010). The non-Lactobacillus species of nonstarter LAB commonly isolated during cheese ripening include Pediococcus acidilactici, Pediococcus pentosaceus, Enterococcus durans, Enterococcus faecalis, Enterococcus faecium, and Leuconostoc spp. (Settanni and Moschetti, 2010). Hundreds of compounds have been implicated in cheese flavor (Fuquay et al., 
2011). The development of flavor in cheese is a complex process originating from a combination of biochemical events such as metabolism of residual lactose, lactate, and citrate; liberation of free fatty acids (FA) through lipolysis and associated catabolic reactions; the degradation of the casein matrix to a range of peptides and free amino acids through proteolysis; and subsequent reactions involved in the catabolism of free amino acids (McSweeney and Sousa, 2000). Milk fat contains high concentrations of short- and intermediate-chain FA, which, when liberated by lipolysis (that is, the enzymatic hydrolysis of fat), contribute directly to cheese flavor. Lipases in cheese are derived from milk, rennet, starter and nonstarter bacteria, or added lipases. Gouda cheese is an internally bacteria-ripened cheese but, when made from pasteurized milk, has no strong lipolytic activities (Marilley and Casey, 2004). The esterase and lipase system of LAB has received less attention than their proteolytic system. Considered weakly lipolytic strains, LAB contain intracellular lipolytic enzymes that are released into the cheese matrix upon cell lysis. Evidence suggests that LAB may be responsible for the liberation of high levels of free FA over extended ripening periods (McSweeney and Sousa, 2000). Some probiotic LAB hydrolyze triglycerides releasing shortand medium-chain FA. Medium-chain FA (C6 to C14) have been described as beneficial to patients who show problems with nutrient absorption, metabolic disorders, cholesterol, and malnutrition (Kris-Etherton and Fleming, 2015). Some probiotic LAB could alleviate esterase or lipase deficiency in the digestive tract during digestion (Pezzilli, 2009). Strains including Lactobacillus helveticus, Lactobacillus bulgaricus, Lactobacillus lactis, and Lactobacillus acidophilus have been described as containing complex systems of intracellular lipolytic and esterolytic enzymes involved in the dairy products. Lactobacillus lactis and L. acidophilus strains have been distinguished for their higher esterase activities (El Soda et al., 1986).

Although the pediococci genus has been studied mainly in relation to its action in cheese, recent focus on the human microbiome and the concomitant benefits of dairy foods and LAB as probiotics has shed light on some important beneficial aspects of these organisms. For example, Shi et al. (2017) reported that among many probiotic LAB, only administration of Lactobacillus salivarius or P. pentosaceus prevented liver fibrosis and downregulated the hepatic expression of profibrogenic genes in rats with CCl4-induced liver cirrhosis, by protecting the intestinal barrier (Shi et al., 2017). Another example is $P$. acidilactici HA-6111-2, isolated from a food matrix. This has been described as a potential probiotic because it did not produce virulence factors, had no significant antibiotic resistance, and survived simulated gastrointestinal tract conditions (Barbosa et al., 2015). Additional evidence of the importance of pediococci in human health and microbiome health is exemplified in the recent patent of Carlin et al. (2018), which describes the mechanism of beneficial action in the gastrointestinal tract. These and other recent reports focused on the membrane action of pediococci led us to explore in more detail the basis for the interaction of these bacteria and the phospholipids (PL) in milk, which seem to have relevance in the symbiosis between milk and LAB as means to improve the human microbiome (Chikindas, Garciagarcera et al., 1993; Annous, Kozempel et al., 1999; Davender et al., 2012; Kaur and Tiwari 2018; and Dubey et al., 2019).

Phospholipases (PLase) are lipolytic esterases that cleave glycerophospholipids, or molecules containing 2 FA esterified to glycerol and a polar head group. The most abundant polar head groups contain a phosphate combined with either choline, ethanolamine, serine, or inositol. Phospholipases are classified according to their substrate cleavage site: carboxyl ester acyl hydrolases (PLA, PLB, PLC, and PLD) or lysophospholipase (LPLA). It has been found that PLA, PLB, and LPLA can cleave FA at the sn- 1 or sn-2 position on the glycerol; PLC and PLD are phosphoric diester hydrolases that cleave glycerol- or alcohol-oriented phosphodiester bonds, respectively; PLC releases the phosphorylated head group and diacylglyceride; and PLD cleaves the terminal phosphodiester bond, releasing the head group and phosphatidic acid (Flores-Díaz et al., 2016).

\section{MATERIALS AND METHODS}

\section{Strain and Growth Conditions}

The $P$. acidilactici strain was isolated from Gouda cheese (Sargento, Plymounth, WI) and identified by 16S rRNA sequencing as P. acidilactici OSU-PECh-3A, as described previously (García-Cano et al., 2019). The strain was stored at $-20^{\circ} \mathrm{C}$ in cryo-vials containing de Man, Rogosa, and Sharpe broth (MRS; Difco, Franklin Lakes, NJ) and glycerol (80/20\%, vol/vol). The P. acidilactici was reactivated by adding $10 \mu \mathrm{L}$ of preserved cells to $10 \mathrm{~mL}$ MRS broth and incubating at $37^{\circ} \mathrm{C}$, without stirring, for $12 \mathrm{~h}$. Then, $1 \mathrm{~mL}$ of inoculum was transferred to $100 \mathrm{~mL}$ of fresh medium and incubated under the same conditions. The cells were pelleted by centrifugation at $10,000 \times g$ at $4^{\circ} \mathrm{C}$ for $15 \mathrm{~min}$ (Centrifuge 5415R, Eppendorf, Hamburg, Germany) and washed 2 times with $30 \mathrm{~mL}$ of Tris- $\mathrm{HCl} 50 \mathrm{mM}$ pH 7.6 buffer. The cells were then used for the intracellular protein extraction. 


\section{Localization of Enzymatic Activity and Assay Description}

The pellet was suspended in Tris- $\mathrm{HCl} 50 \mathrm{mM} \mathrm{pH}$ 7.6 buffer and adjusted to an optical density $\left(\mathrm{OD}_{600 \mathrm{~nm}}\right)$ of 5.0 to 5.5 in a spectrophotometer (Multiskan Go, Thermo Fisher Scientific, Waltham, MA). The cellular suspension was ultrasonically ruptured using the following parameters: 20 cycles of 20 -s sonication at 20 $\mathrm{Hz}$ followed by 20-s rest (Branson Sonifier 450, Thermo Fisher Scientific). The resulting sample was centrifuged at $13,000 \times g$ at $4^{\circ} \mathrm{C}$ for $30 \mathrm{~min}$. The soluble section was recovered and named the intracellular fraction. The lipolytic activity of the intracellular fraction was determined using $\alpha$-naphthyl acetate as a substrate (Sigma-Aldrich, St. Louis, MO) and Fast Red TR (Sigma-Aldrich) for color development (Kakariari et al., $2000)$. Briefly, $50 \mu \mathrm{L}$ of intracellular fraction was mixed with $50 \mu \mathrm{L}$ of substrate $(2 \mathrm{mg} / \mathrm{mL})$ and incubated at $37^{\circ} \mathrm{C}$ for $10 \mathrm{~min}$. Subsequently, $50 \mu \mathrm{L}$ of Fast Red TR ( 5 $\mathrm{mg} / \mathrm{mL}$ ) was added and mixed, and the absorbance was measured at $560 \mathrm{~nm}$ in a microplate reader (Multiskan Go, Thermo Fisher Scientific). One unit was defined as the amount of the enzyme yielding $\Delta \mathrm{Abs}_{560}=0.01 / \mathrm{min}$ at $37^{\circ} \mathrm{C}$, and the specific activity was established as the number of units per milligram of protein.

\section{Protein Profile and Zymograms}

Native 10\% PAGE was performed and stained with Bio-Safe Coomassie (Bio-Rad, Hercules, CA). Following the procedure of Peña-Montes et al. (2013) with some modifications, $\alpha$-naphthyl acetate (Sigma-Aldrich) was used as the substrate for the zymograms. Briefly, after running native PAGE, the gel was washed in $50 \mathrm{~mL}$ of deionized water and incubated with $2.5 \%$ Triton X-100 (Sigma-Aldrich) for $30 \mathrm{~min}$. The gel was then incubated in $0.6 \mathrm{mg} / \mathrm{mL}$ of $\alpha$-naphthyl acetate (distilled water:acetone at $95: 5 \mathrm{vol} / \mathrm{vol}$ ) for $1 \mathrm{~h}$ at $37^{\circ} \mathrm{C}$, followed by 2 deionized water washes. Finally, the Fast Red TR solution $(0.8 \mathrm{mg} / \mathrm{mL}$ in water:Triton X-100 at 97.5:2.5 $\mathrm{vol} / \mathrm{vol}$ ) was added to the gel until brown bands appeared. The band displaying activity was analyzed using a ChemiDoc Touch imaging system (Bio-Rad). To determine the molecular mass of each band, the Precision Plus Protein standard was used (Bio-Rad).

\section{Purification of the Enzyme with Esterase Activity}

To purify the lipolytic enzyme, the intracellular fraction was concentrated through ultrafiltration using Amicon Ultra Centrifugal Filters (15 mL, 50-kDa cutoff, Millipore, Billerica, MA). After this process, the sample was loaded on an Enrich SEC 650 high-resolution size- exclusion column (Bio-Rad) using the NGC Discover 10 Chromatography System (Bio-Rad), with the following conditions: $1 \mathrm{~mL} / \mathrm{min}$ flow rate for $45 \mathrm{~min}$ in a $10 \mathrm{~m} M$ Tris- $\mathrm{HCl}$ buffer $\mathrm{pH}$ 7.6. Esterase activity was assayed in each fraction as previously described. The fractions that showed activity were concentrated using a Vacufuge Plus vacuum concentrator (Eppendorf) and analyzed via PAGE and zymogram assays. The band intensity was calculated using Image Lab software version 6.0.1 (Bio-Rad).

\section{Protein Concentration and Protein Identification via LC-MS/MS}

The protein concentration was determined following the Bradford Protein Assay Kit protocol (Bio-Rad). Bovine serum albumin was used as a protein standard and for calibration. After purification, the protein band was excised from the gel and sent for sequencing analysis at the Campus Chemical Instrument Center, Mass Spectrometry and Proteomics Facility, at The Ohio State University (Columbus, $\mathrm{OH}$ ). The protein band was subjected to in-gel trypsin digestion, and the resulting peptides were analyzed via capillary liquid chromatography (LC)-MS/MS. The peptide fragments generated by tandem MS were compared with the MASCOT database to obtain the amino acid sequence. Proteins with at least 2 peptide fragments matching to the database were considered reliable identification hits.

\section{Gene Identification and Accession Number in GenBank}

Previously, P. acidilactici genomic DNA (gDNA) had been extracted, sequenced, and analyzed (García-Cano et al., 2019). This gDNA was used as a template to amplify the specific gene for the phosphoesterase, using the forward primer PaciPE-F 5'-GTGAAGTTTATGCACGTAGCGGAC-3' and reverse primer PaciPE-R 5'-CACTCGTTTATCATCCCCCAGC-3'. The PCR reaction was performed using 1.0 U Platinum Taq DNA Polymerase (Thermo Fisher Scientific), $0.4 \mathrm{mM}$ of each primer, and $2.5 \mathrm{mM} \mathrm{MgSO}$. The following conditions were used: 1 cycle at $94^{\circ} \mathrm{C}$ for $3 \mathrm{~min}$, followed by 30 cycles at $94^{\circ} \mathrm{C}(30 \mathrm{~s}), 57^{\circ} \mathrm{C}(30 \mathrm{~s}), 72^{\circ} \mathrm{C}(90 \mathrm{~s})$, and a final cycle at $72^{\circ} \mathrm{C}$ for $2 \mathrm{~min}$ in a Thermal Cycler Eco (Eppendorf). The amplicon was purified using a Wizard SV Gel and PCR Clean-Up Kit (Promega, Madison, WI) and sent for sequencing to Macrogen Inc. (Seoul, South Korea). The sequence obtained was compared with the GenBank database (https://www .ncbi.nlm.nih.gov/genbank/) using the Basic Local Alignment Search Tool (BLAST) algorithm available 
from the National Center of Biotechnology Information (http://blast.ncbi.nlm.nih.gov/; date of query: August 2019). The sequence ppe 85 was submitted to GenBank and its accession number is MK967459.

\section{Biochemical Characterization}

Substrate Specificity. Different p-nitrophenyl substrates $[p$-nitrophenyl acetate $(\boldsymbol{p}$-NA), $p$-nitrophenyl butyrate $(p$-NB), $p$-nitrophenyl octanoate $(p$-NO), $p$-nitrophenyl dodecanoate ( $p$-ND), $p$-nitrophenyl myristate $(p-\mathrm{NM})$, and $p$-nitrophenyl palmitate $(p-\mathrm{NP})$; Sigma-Aldrich] were used to test the enzyme specificity according to Esteban-Torres et al. (2014). Briefly, 50 $\mu \mathrm{L}$ of the intracellular fraction was mixed with $100 \mu \mathrm{L}$ of each substrate $(10 \mathrm{mM})$, and the absorbance was measured at $410 \mathrm{~nm}$ in a microplate reader at $37^{\circ} \mathrm{C}$ at 1-min intervals over $30 \mathrm{~min}$. One unit was defined as the quantity of enzyme that releases $1 \mu \mathrm{mol}$ of $p$ nitrophenol per minute at $37^{\circ} \mathrm{C}$.

Effects of $p H$ and Temperature on Enzyme Activity. To determine the optimal $\mathrm{pH}$ of the isolated protein, the following buffers were used according to García-Cano et al. (2015): citric acid, acetic acid, BisTris, Tris, $N$-cyclohexyl-2-aminoethanesulfonic acid, and $N$-cyclohexyl-3-aminopropanesulfonic acid $(\mathrm{pH}$ ranges 2.1 to $4.1,3.8$ to $5.8,5.8$ to $7.2,7.0$ to $9.0,8.6$ to 10.0 , and 9.7 to 11.1, respectively). Each buffer was mixed to a final concentration of $20 \mathrm{~m} M$, and $\mathrm{pH}$ was adjusted to $3,4,5,6,7,8,9,10$, and 11 . The assay consisted of $10 \mu \mathrm{L}$ of $p$-NA $(100 \mathrm{mM})$ and $90 \mu \mathrm{L}$ of each buffer. The enzymatic activity was initiated by addition of $50 \mu \mathrm{L}$ of the purified enzyme to prevent a premature reaction. The enzyme with Tris- $\mathrm{HCl} 20 \mathrm{mM}$ pH 7.6 buffer was used as a control. For the temperature assay, enzyme activity was measured using $50 \mu \mathrm{L}$ of purified protein and $100 \mu \mathrm{L}$ of $p$-NA $(10 \mathrm{~m} M)$. The absorbance was measured at $410 \mathrm{~nm}$ at different temperatures (37, $45,50,60,70,80$, and $90^{\circ} \mathrm{C}$ ) for 1-min intervals over 30 min. Enzyme not subjected to thermal treatment was used as a control (room temperature).

Effects of Mono- and Divalent Ions, Detergents, and Reducing and Chelating Agents on Activity. The following reagents were used to evaluate the effect on enzymatic activity: $\mathrm{K}^{+}, \mathrm{Ca}^{2+}, \mathrm{Mg}^{2+}$, and $\mathrm{Zn}^{2+}$ as mono- and divalent ions, respectively; Tween-20, Tween-80, Triton X-100, and SDS as detergents; $\beta$-mercaptoethanol and dithiothreitol as reducing agents; and EDTA and EGTA as chelating agents. Reagents were prepared at $150 \mathrm{~m} M$ concentrations (all reagents purchased from Sigma-Aldrich). Forty microliters of the purified enzyme were mixed with $10 \mu \mathrm{L}$ of each reagent solution and $100 \mu \mathrm{L}$ of $p$-NA $(10 \mathrm{mM})$. The reaction mix was incubated for 60 min at $37^{\circ} \mathrm{C}$.
The enzyme without added reagent solution was used as a control.

Phospholipid Hydrolysis. Hydrolysis of PL was investigated using the major PL classes present in milk; specifically, 16:0 PC (1,2-dipalmitoyl-sn-glycero3-phosphocholine); 16:1 PE (1,2-dipalmitoleoyl-snglycero-3-phosphoethanolamine); 18:0 PI (1,2-distearoyl-sn-glycero-3-phosphoinositol, ammonium salt); 16:0 PS (1,2-dipalmitoyl-sn-glycero-3-phospho-L-serine, sodium salt); SM (sphingomyelin, milk, bovine); and 16:0 PA (phosphatidic acid; 1,2-dipalmitoyl-sn-glycero3-phosphate, sodium salt) were used to generate a standard curve. All PL were purchased from Avanti Polar Lipids Inc. (Alabaster, AL). The measurement for hydrolysis of each PL was performed according to Dippe and Ulbrich-Hofmann (2009), using the binding properties of PA to $\mathrm{Fe}^{3+}$ ions. Briefly, each substrate was dissolved in $10 \mathrm{~m} M$ Triton $\mathrm{X}-100$ to reach a final concentration of $10 \mathrm{~m} M$ substrate. Then, $40 \mu \mathrm{L}$ of isolated protein was mixed with $40 \mu \mathrm{L}$ of substrate solution and incubated at $37^{\circ} \mathrm{C}$ for $2 \mathrm{~h}$ with gentle shaking. After incubation, the reaction mixture was stopped with $200 \mu \mathrm{L}$ of FeSal solution $\left(1 \mathrm{mM} \mathrm{FeCl}{ }_{3}\right.$ and $6 \mathrm{mM}$ sodium salicylate in $500 \mathrm{~m} M$ formic acid/NaOH, pH 4.0) and incubated for $5 \mathrm{~min}$ at room temperature. The absorbance was measured at $490 \mathrm{~nm}$ in a microplate reader, and the amount of PA formed was calculated using a standard curve of PA. One unit was defined as the quantity of enzyme that releases $1 \mu \mathrm{mol}$ of $\mathrm{PA} / \mathrm{min}$ at $37^{\circ} \mathrm{C}$.

\section{Statistical Analysis}

All experiments were performed in triplicate with 3 independent experiments. Statistical analysis was performed using SPSS software (IBM Inc., Armonk, NY). One-way ANOVA followed by least significant difference (LSD) test and paired $t$-tests were applied to detect significant difference $(P<0.05)$.

\section{RESULTS AND DISCUSSION}

The results presented here represent a detailed characterization, localization, and identification of a PLase in $P$. acidilactici with a very unusual spectrum activity on PL. Comparison with the esterases and lipases of other LAB strains in our laboratory collection shows that this enzyme not only shows high activity but also seems to cleave all PL present in milk, albeit at different rates. If we consider its origin, it may be that the role of this strain in cheese, very likely based in this esterase and lipase activity, is that of generating particular aromas and flavors in mature Gouda cheese. If the phosphoesterase activity presented by this bac- 
A

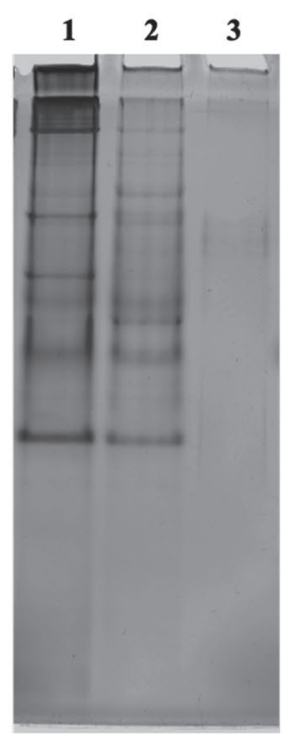

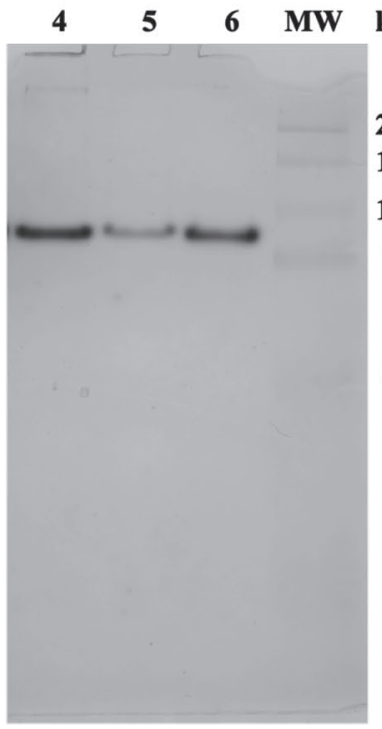

B
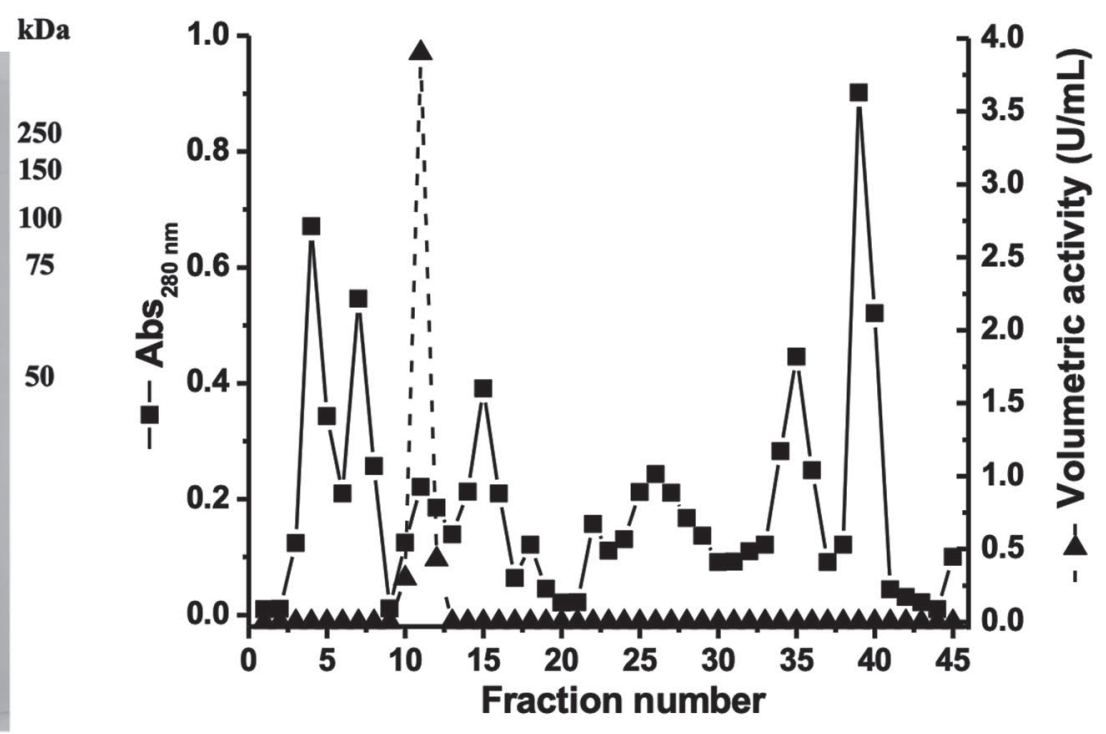

Figure 1. Purification of intracellular phosphoesterase enzyme from Pediococcus acidilactici OSU-PECh-3A. (A) Native PAGE: lane 1 = intracellular fraction; lane $2=$ intracellular fraction after ultrafiltration; lane 3 = purification of phosphoesterase. Lanes 4,5 , and 6 correspond to the intracellular fraction, intracellular fraction after ultrafiltration, and purification of phosphoesterase, respectively, in zymograms. MW $=$ molecular weight broad range. (B) Chromatogram obtained from size-exclusion column. Abs = absorbance.

terium prevails in the human gut, it could act on PL found in food, producing metabolites for easier absorption or enhanced digestion.

\section{Intracellular Activity and Purification}

Lactic acid bacteria contain intracellular esterases and lipases that are released into the cheese matrix upon cell autolysis during maturation (McSweeney and Sousa, 2000). Several intracellular esterases and lipases have been reported in different LAB (Thierry et al., 2017); however, only a few reports have been described in P. acidilactici (García-Cano et al., 2019).

After cell disruption, the intracellular fraction was concentrated through ultrafiltration and analyzed using native PAGE and zymograms. In Figure 1A, lane 1 shows the intracellular fraction before concentration, and lane 2 shows the protein profile after ultrafiltration. Similarly, in Figure 1A, lanes 4 and 5 show the enzymatic activity by zymogram, exhibiting bands around $85 \mathrm{kDa}$. The ultrafiltered sample was loaded on a size-exclusion molecular weight column, and the activity was monitored using the esterase assay. The chromatogram in Figure 1B shows that fraction 11 presents the highest enzymatic activity. The protein profile of native PAGE shows 3 bands (Figure 1A, lane 3), one with molecular mass around $85 \mathrm{kDa}$ corresponding to esterase activity (Figure 1A, lane 6), which represent $33 \%$ of the total protein present in the fraction. The second and third protein correspond to 36 and $31 \%$ of the protein present in 80 - and $77-\mathrm{kDa}$ molecular weight, respectively. Image Lab software (Bio-Rad) was used to calculate the purity of each band based on optical density readings. With 3 purification steps, an active fraction that represents $1.8 \%$ yield increased in purity by a factor of 62.5 compared with the crude intracellular fraction (Table 1).

Many bacterial intracellular esterases and lipases have been purified (Javed et al., 2018); however, the enzyme studied in this work shows differences in biochemical

Table 1. Purification of 85-kDa lipase from Pediococcus acidilactici OSU-PECh-3A

\begin{tabular}{lccrc}
\hline Step & $\begin{array}{c}\text { Total protein } \\
(\mathrm{mg} \pm \mathrm{SD})\end{array}$ & $\begin{array}{c}\text { Total activity } \\
(\mathrm{U} \pm \mathrm{SD})\end{array}$ & $\begin{array}{c}\text { Specific activity } \\
(\mathrm{U} / \mathrm{mg} \pm \mathrm{SD})\end{array}$ & $\begin{array}{c}\text { Purification } \\
(\text { fold })\end{array}$ \\
\hline Intracellular fraction & $11.9 \pm 11$ & $115 \pm 3.8$ & $3.5 \pm 0.4$ & $\begin{array}{c}\text { Yield } \\
(\%)\end{array}$ \\
Ultrafiltration (50 kDa) & $2.1 \pm 2.1$ & $35 \pm 2.1$ & $43.4 \pm 2.2$ & 1 \\
Size exclusion (Enrich $\left.650^{1}\right)$ & $0.03 \pm 0.001$ & $2.1 \pm 0.2$ & $218 \pm 7.2$ & 100 \\
\hline
\end{tabular}

${ }^{1}$ Enrich SEC 650 high-resolution size-exclusion column (Bio-Rad, Hercules, CA). 


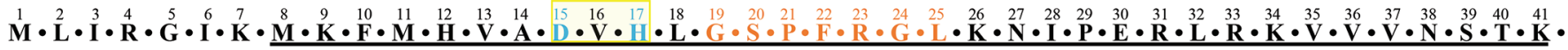

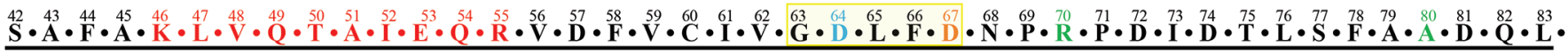

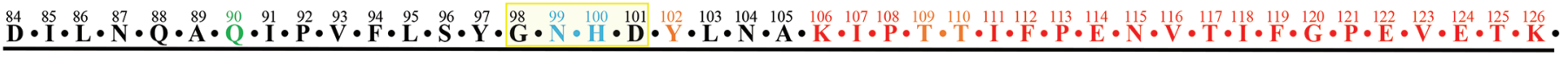

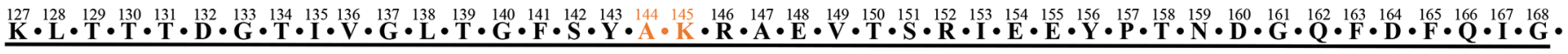

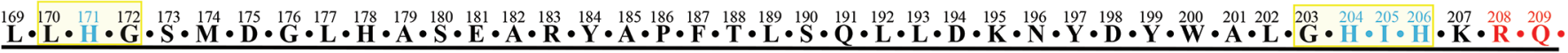

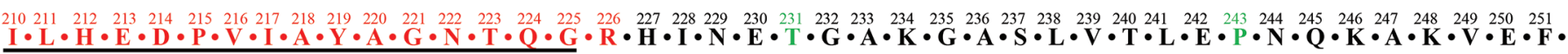

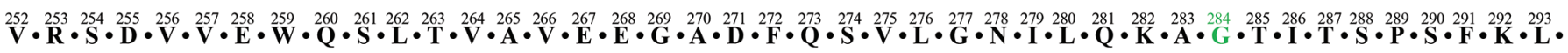

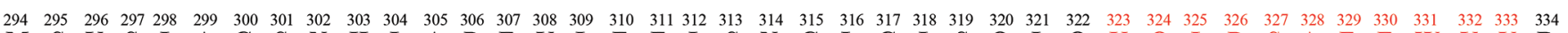

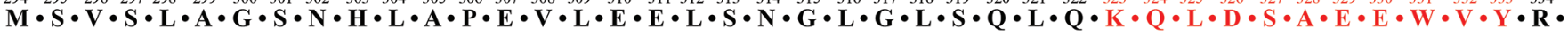
$\mathbf{I} \cdot \mathbf{L} \cdot \mathbf{L} \cdot \mathbf{K} \cdot \mathbf{V} \cdot \mathbf{D} \cdot \mathbf{E} \cdot \mathbf{Q} \cdot \mathbf{Q} \cdot \mathbf{P} \cdot \mathbf{V} \cdot \mathbf{F} \cdot \mathbf{S} \cdot \mathbf{E} \cdot \mathbf{L} \cdot \mathbf{D} \cdot \mathbf{R} \cdot \mathbf{T} \cdot \mathbf{T} \cdot \mathbf{Y} \cdot \mathbf{W} \cdot \mathbf{Q} \cdot \mathbf{Q} \cdot \mathbf{Q} \cdot \mathbf{A} \cdot \mathbf{A} \cdot \mathbf{A} \cdot \mathbf{E} \cdot \mathbf{Q} \cdot \mathbf{V} \cdot \mathbf{F} \cdot \mathbf{T} \cdot \mathbf{P} \cdot \mathbf{K} \cdot \mathbf{K} \cdot \mathbf{T} \cdot \mathbf{V} \cdot \mathbf{Q} \cdot \mathbf{Q} \cdot \mathbf{K} \cdot \mathbf{Q} \cdot \mathbf{L} \cdot \mathbf{L} \cdot \mathbf{G} \cdot \mathbf{R} \cdot \mathbf{L} \cdot \mathbf{L} \cdot \mathbf{M} \cdot \mathbf{M}^{356}$

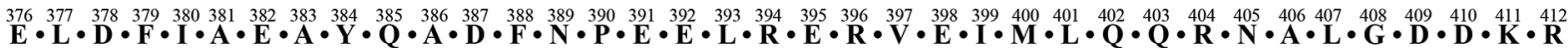

Figure 2. Amino acid sequence identified via liquid chromatography (LC)-MS/MS and analysis of phosphoesterase from Pediococcus acidilactici OSU-PECh-3A. Underlining $=$ hypothetical Ser/Thr phosphatase family; red = amino acid residues identified by LC-MS/MS; green $=P$. acidilactici OSU-PECh-3A identified in silico, compared with other Pediococcus species; orange = DNA binding sites; blue = conserved active site for binding 2 metal ions, such as $\mathrm{Fe}^{3+}, \mathrm{Mg}^{2+}, \mathrm{Mn}^{2+}$, and $\mathrm{Zn}^{2+}$, coordinated with asparagine, aspartate, and histidine residues; yellow boxes $=$ phosphodiesterase motifs.

and structural properties. The most commonly reported intracellular esterases and lipases from LAB have similar molecular weights. From Lactobacillus plantarum WCFS1, a lipase with $28-\mathrm{kDa}$ molecular weight was cloned and expressed (Esteban-Torres et al., 2014). In L. lactis ssp. cremoris ACA-DC127, an esterase of $68 \mathrm{kDa}$ was reported (Tsakalidou and Kalantzopoulos, 1992). On the other hand, 3 esterase proteins from Pseudomonas spp. were reported with similar molecular weights of 30,33 , and $50 \mathrm{kDa}$ and were grouped into 3 broad categories based on molecular weight. In this study, the $85-\mathrm{kDa}$ enzyme observed in a native zymogram completely lost activity under SDS conditions. In addition, we performed PAGE under semi-denaturing conditions (SDS only, without $\beta$-mercaptoethanol) and the gel showed an intense band around $45 \mathrm{kDa}$ (data not shown). This implies that the enzyme may be a dimer in the native structure to present phosphoesterase activity. Holland and Coolbear (1996) reported a holoenzyme tributyrin esterase from L. lactis ssp. cremoris E8 with an apparent tetramer of $109-\mathrm{kDa}$ and $29-\mathrm{kDa}$ molecular mass for each subunit.

\section{Gene and Protein Identification}

The gDNA from $P$. acidilactici OSU-PECh-3A was extracted and used as DNA template for amplification of a 1,233-bp fragment corresponding to the complete gene for the phosphoesterase (ppe85; GenBank accession number MK967459). The Translate Tool in the ExPASy Proteomics Server (Swiss Institute of Bioin- formatics, Lausanne, Switzerland) was used to obtain the amino acid sequence. A virtual translation and BLAST database were used to compare the deduced amino acids sequence. Figure 2 shows the bioinformatic analysis performed and the total amino acid sequence obtained. The peptides shown in red represent the amino acid sequences obtained after trypsin digestion, identified by LC-MS/MS. These peptides covered $18.5 \%$ of the sequence and had $100 \%$ identity to a Ser/ Thr phosphatase family protein within the genome of P. acidilactici DSM 20284 (protein BLAST-NCBI, access: EFL96070.1). Using the ProtParam software (ExPASy), a molecular weight of $45.9 \mathrm{kDa}$ and isoelectric point $(\mathrm{pI})$ of 5.12 was predicted.

The underlined residues in Figure 2 represent a hypothetical Ser/Thr phosphatase protein family with an N-terminal Mre11 region and metallophosphatase superfamily, which includes metallophosphoesterases, phosphodiesterases, binuclear metallophosphoesterases, and acid sphingomyelinases. The Mre11 protein $\mathrm{SbcD}$ from Escherichia coli) is a subunit that plays a vital role in cellular processes in prokaryotes and eukaryotes and belongs to the metallophosphatase superfamily that includes YfcE-like phosphodiesterases, purple acid phosphatases, Mre11/SbcD-like exonucleases, and acid sphingomyelinases, among others (Miller et al., 2007). Also in Figure 2, green indicates the 6 variable amino acid residues found in $P$. acidilactici OSU-PECh-3A compared with one other Pediococcus species (P. acidilactici DSM 20284) in the database. Three different amino acids residues were found in the metallophospha- 
tase superfamily domain, and the differences are not expected to affect the lipolytic activity. The physicochemical properties of each different amino acid residue are described as follows. In the Ser-70 position, Arg (R) was found in the OSU-PECh-3A sequence. Whereas Ser-70 is a polar, positive residue, Arg is a polar, noncharged amino acid. The residues that were not considerably different were Val-80 by an Ala amino acid, and both residues show hydrophobic characteristics. In position $90 \mathrm{Gln}(\mathrm{Q})$ residue was found in the OSU-PECh$3 \mathrm{~A}$ sequence, which is different from the $P$. acidilactici DSM 20284 sequence (Lys, K). A Gln residue is a polar, non-charged amino acid, whereas a Lys residue is a polar, positive amino acid. A polar amino acid (Thr, T) was found in the 231 position of the OSU-PECh-3A sequence, whereas in DSM 20284 a non-polar residue (Pro, P) was found. Two non-polar amino acids were identified at 243 and 284 (Pro and Gly, respectively) of the $P$. acidilactici DSM 20284 sequence, and Ser and Asn residues were substituted in the same positions of the OSU-PECh-3A sequence. These last amino acids are polar, non-charged residues. However, it is likely that the variant amino acid residues found do not have major effects, because we observed enzymatic activity in P. acidilactici OSU-PECh-3A.

The orange residues in Figure 2 represent DNA binding sites that play a key role in DNA reparation (Williams et al., 2008). Recently, these DNA binding properties have been used as a biosensor for control and quantification of effector compounds such as heavy metals and toxins (Landete and Arqués, 2017). The amino acids depicted in blue show conserved active sites identical to known metal ion-binding sites, which bind $\mathrm{Fe}^{3+}, \mathrm{Mg}^{2+}, \mathrm{Mn}^{2+}$, and $\mathrm{Zn}^{2+}$, coordinated by asparagine, aspartate, and histidine residues (Hopfner et al., 2001). Hopfner et al. (2001) reported an Mre11 active site with phosphodiesterase activity from Pyrococcus furiosus. It was observed that $2 \mathrm{Mn}^{2+}$ ions are coordinated by 7 amino acid residues (Asp- 8 , His10, Asp-49, Asn-84, His-173, Hist-206, and His-208). The metallophosphoesterase that was identified in this study shows the same conserved domains in different positions of the sequence, specifically Asp-15, His-17, Asp-64, Asn-99, His-171, His-204, and His-206. The phosphodiesterase motifs were also identified (Figure 2, yellow boxes).

This detailed comparison of metallophosphoesterases of other bacteria has significance in validating the enzyme studied in this work with activity on PL, although the genetic variation of the distinct positions of amino acids indicates a variant of the strain. We hypothesize that this is partially due to symbiosis with other bacteria, perhaps LAB that aid in the very complex metabolism of cheese flavor generation. Furthermore, this activity may be advantageous to the survival of this strain in a competitive microbiome such as that of the human gut.

\section{Biochemical Characterization}

Substrate Specificity. After purification, the enzyme was exposed to different $p$-nitrophenyl substrates to determine specificity. Enzymatic activity is dependent on the chain length of FA (Peña-Montes et al., 2013). Figure $3 \mathrm{~A}$ indicates that the purified enzyme had high affinity for FA with a 3 carbon (C3) chain ( $p$-NA) with $100 \%$ relative activity. Additionally, the enzyme shows 51 and $27 \%$ relative hydrolysis against $\mathrm{FA}$ with $\mathrm{C} 4$ and $\mathrm{C} 8$ chains ( $p$ - NB and $p$-NO), respectively. The hydrolysis activity on long-carbon chains ( $p$-ND and $p$-NM) was low, with 5 and $6 \%$ relative activity, respectively. The enzyme did not show activity on C16 FA, such as $p$-NP. Other lipolytic proteins have been reported with different preferences of $p$-nitrophenyl substrates, where C16 and C18 carbon chains are commonly used and cleaved (Thierry et al., 2017); however, many esterases show preference for short-chain FA with low hydrolysis of milk fat (Holland et al., 2005). These results clearly indicate a high degree of adaptation of this strain to cheese and dairy lipids, as these FA are not common elsewhere. It will be of great importance for our future research to measure or characterize its role and effect in the human gut microbiome or in models for digestion and absorption of the metabolites produced by this strain.

$p H$ and Temperature Effect. With a few exceptions, esterases and lipases of LAB are optimally active at pH 7.0 to 8.5 (Esteban-Torres et al., 2014). Figure $3 \mathrm{~B}$ shows that the optimal $\mathrm{pH}$ is 8.0 , with $15 \%$ activity loss at $\mathrm{pH}$ 9.0. At pH 10.0 and 11.0, only $20 \%$ of the activity was retained; below $\mathrm{pH} 8.0$, activity dramatically decreased, with $70 \%$ reduction. The enzyme did not show activity at acidic $\mathrm{pH}(3.0,4.0,5.0$, or 6.0$)$. In general, this effect was related to the ionization properties of the catalytic triad. Specifically, histidine plays an important role in the nucleophilic character to a greater degree than the other amino acids in alkaline conditions (Roussel et al., 1999).

The optimal temperature of the phosphoesterase enzyme was $37^{\circ} \mathrm{C}$. Only $8 \%$ activity was lost at 40 and $50^{\circ} \mathrm{C}$, with no significant difference, whereas at 60,70 , and $80^{\circ} \mathrm{C}$, between 86 and $89 \%$ activity remains, and, surprisingly, the enzymatic activity is stable at $90^{\circ} \mathrm{C}$ (Figure 3C). This demonstrates that the enzyme is active over a broad temperature range, which parallels the profiles reported for other LAB esterases and lipases. For example, a lipase with optimal temperature at $30^{\circ} \mathrm{C}$ in L. plantarum WCFS1 was characterized (Esteban- 

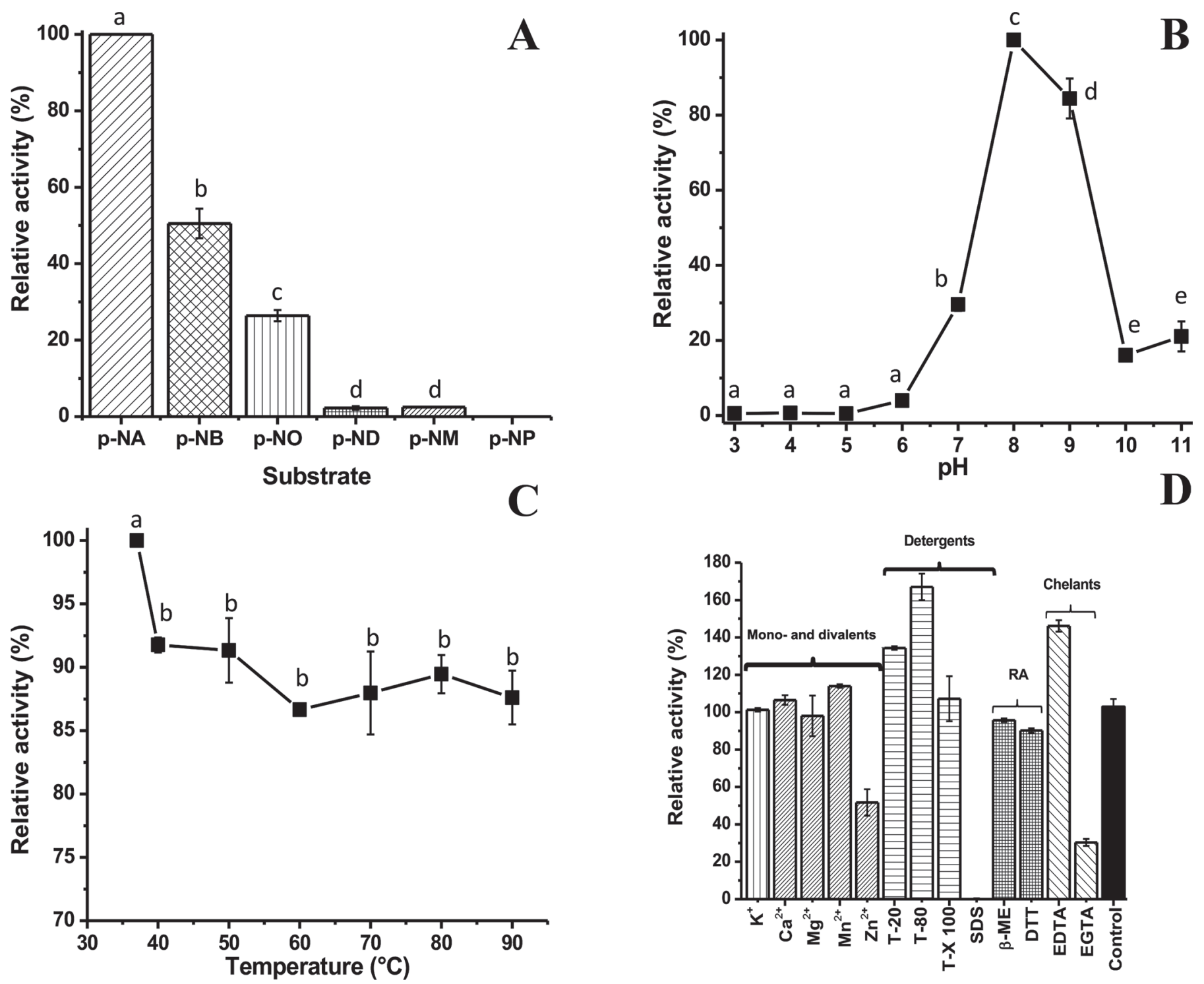

Figure 3. Biochemical characterization of the phosphoesterase. (A) Substrate profile using $p$-nitrophenyl substrates: $p$-NA $=p$-nitrophenyl acetate; $p$ - $\mathrm{NB}=p$-nitrophenyl butyrate; $p$ - $\mathrm{NO}=p$-nitrophenyl octanoate; $p$ - $\mathrm{ND}=p$-nitrophenyl dodecanoate; $p$ - $\mathrm{NM}=p$-nitrophenyl myristate; $p$-NP $=p$-nitrophenyl palmitate. (B) Effect of $\mathrm{pH}$ and (C) effect of temperature on activity. (D) Effects of mono- and divalent ions, detergents, reducing agents (RA), and chelants. Control $=$ sample treated without agents. Error bars represent SD of 3 independent experiments. Different lowercase letters indicate significance differences $(P<0.05)$. T-20 $=$ Tween-20; T-80 $=$ Tween-80; T-X 100 $=$ Triton X-100; beta-ME $=\beta$-mercaptoethanol; DTT $=$ dithioerythritol.

Torres et al., 2014); in L. lactis ssp. lactis NCDO 763, the optimal temperature for a specific butanoic lipase was $55^{\circ} \mathrm{C}$ (Chich et al., 1997); another lipase in L. plantarum DSMZ 12028 was highly temperature-resistant and retained $90 \%$ lipolytic activity after $30 \mathrm{~min}$ of incubation (Lopes et al., 2002). It is not unusual for these LAB enzymes to have optimal activity at temperatures in the mesophilic range. Our data indicates that this is also the case for this enzyme, and, as such, it is important to mention that the enzyme would survive thermal treatments and provide activity if desired by proces- sors. Furthermore, basic pH and thermostable esterases and lipases are tremendously attractive for industrial applications, which can be used for agrochemical processes, cosmetics, and flavor production (Hernández et al., 2005).

Effects of Mono- and Divalent Ions, Detergents, and Reducing and Chelating Agents. The addition of monovalent ions $\left(\mathrm{K}^{+}\right)$does not affect the enzyme activity, whereas the divalent ions $\mathrm{Ca}^{2+}$ and $\mathrm{Mn}^{2+}$ increase enzymatic activity by 8 and $15 \%$, respectively. Conversely, the addition of $\mathrm{Zn}^{2+}$ resulted in $50 \%$ 
loss of phosphoesterase activity (Figure 3D). Similar to other esterases and lipases from LAB, divalent ions such as $\mathrm{Ca}^{2+}, \mathrm{Mg}^{2+}$, and $\mathrm{Mn}^{2+}$ have no negative effect on enzyme activity, likely due to the presence of an Asp- or Glu- amino acid residue, which gives a negative charge in the catalytic site. In the lipase produced by Leuconostoc mesenteroides ssp. mesenteroides, cations such as $\mathrm{Mg}^{2+}$ or $\mathrm{Ca}^{2+}$ cross-link the catalytic triad, which increases enzyme stability (Eko Sukohidayat et al., 2018). Both $\mathrm{Zn}^{2+}$ and $\mathrm{Cu}^{2+}$ cations inhibit lipolytic enzymes because they can interact with additional accessible charged groups, affecting enzyme stability (Rahman et al., 2006).

The addition of detergents increase activity to 135 and $168 \%$ of the original activity for Tween-20 and Tween-80, respectively. Triton-X 100 did not have an effect on enzymatic activity; however, the SDS detergent completely inhibited its activity. Non-ionic detergents (Tween-20, Tween-80, and Triton-X 100) have low hydrophilic/lipophilic balance (HLB) values, which indicates the distribution of detergents between non-polar and polar phases. The HLB is a balance of the size and strength of the hydrophilic and lipophilic moieties of a surfactant molecule. Tween-20, Tween-80, and Triton-X 100 have low HLB values $(16.7,15$, and 13.5, respectively) compared with SDS detergent, which has an HLB value of 40 . In general, low HBL values have no effect on lipolytic activity, and values over 7 indicate greater solubility in water than in oil (Bose and Keharia, 2013; Eko Sukohidayat et al., 2018). In other species, such as Leuconostoc mesenteroides ssp. mesenteroides ATCC 8293, the reported lipase behavior was similar, as Tween-20, Tween-80, and Triton-X 100 induced lipase activity, and SDS reduced enzymatic activity by $21.3 \%$ (Eko Sukohidayat et al., 2018).

Neither reducing agent used in this work ( $\beta$-mercaptoethanol and dithiothreitol) had an effect on phosphoesterase activity, which is similar to the lipase reported in L. plantarum WCFS1 (EstebanTorres et al., 2014). These findings are consistent with the lack of disulfide bonds necessary for maintaining enzyme conformation. In silico analysis indicates that the phosphoesterase found in this study does not have disulfide bonds (DiANNA 1.1; Ferrè and Clote, 2006).

The EDTA metal chelating agent showed a $47 \%$ increase in activity, but EGTA resulted in $70 \%$ loss of lipolytic activity (Figure 3D). In several LAB esterases and lipases, EDTA has a negative effect on lipolytic activity (Lopes et al., 2002; Esteban-Torres et al., 2014); however, in this study this inhibition was not observed as reported for other esterases and lipases. The other $\mathrm{Ca}^{2+}$ metal chelating agent, EGTA, has been reported to decrease lipolytic activities in other species (Pseudo- monas cepacia and Pseudomonas pseudoalcaligenes) due to high affinity to calcium (Svendsen et al., 1995). The observed decrease in activity for the phosphoesterase of P. acidilactici in the presence of EGTA suggests interference between the esterase and substrate.

Phospholipid Hydrolysis. Hydrolysis of different PL by the phosphoesterase is shown in Figure 4. We found that PE $(0.44 \% \pm 0.09 ; \pm \mathrm{SD})$ and PS $(3.9 \% \pm$ 0.32 ) had the lowest and highest hydrolysis, respectively, whereas PC, PI, and SM presented similar PL hydrolysis without significant difference. Bacterial PLase play an important role in metabolic pathways, such as cell signaling, growth, death, and membrane dynamics (Songer, 1997; Rodriguez et al., 2001; Wan et al., 2019). Other PLase, expressed in hepatic and brain tissues, are involved in other metabolic processes and have been shown to reduce high-density lipoprotein levels in plasma (Cohen, 2003). Additionally, the mechanism of phosphoesterase hydrolysis of PL is binding to the lipid surface through interactions with the polar head group rather than with the acyl chain (Chen and Subbaiah, 2007). In milk fat, the most commonly found PL are PE, PC, and SM (Gunstone et al., 1994), and it has been reported that, through PLase activity, PE hydrolysis can release docosahexaenoic acid, 22:6 n-3, which has been found to have numerous benefits to neurological functions and brain development (Chen and Subbaiah, 2007). Additionally, PL hydrolysis products include several cis unsaturated FA, such as oleic, linoleic, linolenic, arachidonic, and docosahexaenoic acids. Furthermore, depending on the site of hydrolysis, lysophospholipids, diacylglycerols, and choline phosphate molecules can be produced, which play important roles in biochemical processes such as digestion and inflammation, and can enhance some metabolic proteins that are essential for long-term cellular responses including differentiation and proliferation (Nishizuka, 1992; De Maria et al., 2007). After hydrolysis, the products can be absorbed and reacylated into PL, and the FA can be used for triacylglycerol synthesis (Murru et al., 2013). In this work, the hydrolysis of PS by the PLase from $P$. acidilactici has potential importance in the release of products such as lysophospholipids, which are absorbed in the intestine and can be reacylated into PS (Tokumura, 2011). The PS may then be converted into other PL, such as PE. Also in this study, the activity on $\mathrm{SM}$ is of note, as it is believed that sphingomyelinases in the human gut are extremely slow-acting enzymes (Zhang et al., 2011). The PLase action in this work may enhance the digestion and metabolism of SM, which induces the production of ceramides that can be further metabolized (by ceramidase and sphingosine kinase) to sphingosine and sphingosine 1-phosphate 


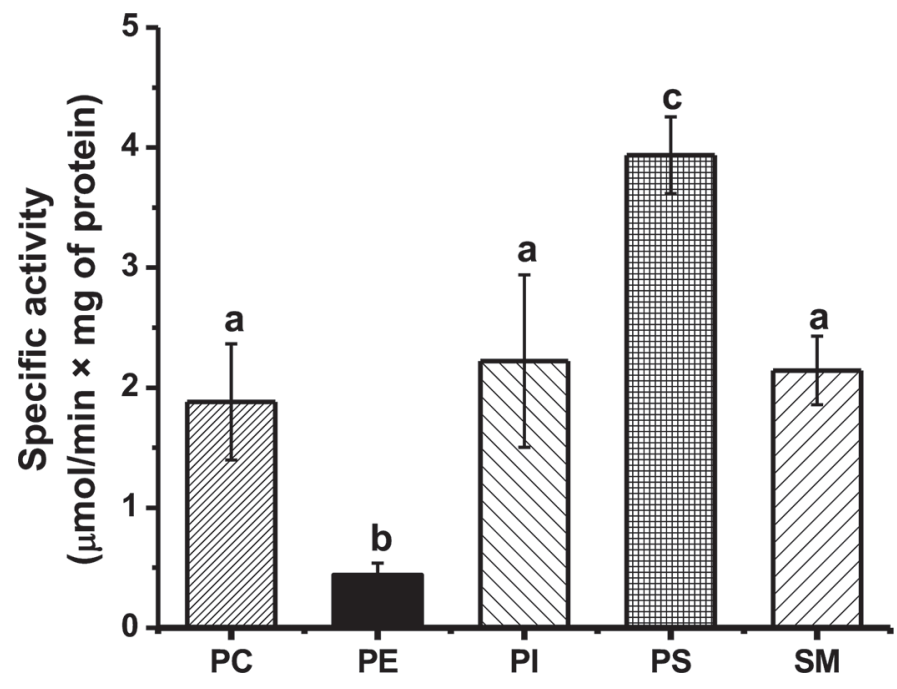

Figure 4. Specific activity of the phosphoesterase from Pediococcus acidilactici OSU-PECh-3A against different phospholipids: 16:0 PC (1,2-dipalmitoyl-sn-glycero-3-phosphocholine); 16:1 PE (1,2-dipalmitoleoyl-sn-glycero-3-phosphoethanolamine); 18:0 PI (1,2-distearoylsn-glycero-3-phosphoinositol); 16:0 PS (1,2-dipalmitoyl-sn-glycero3-phospho-L-serine); SM (sphingomyelin, milk, bovine). Error bars represent SD of 3 independent experiments. Different letters indicate statistical difference $(P<0.05)$.

(De Maria et al., 2007). The products of SM hydrolysis by LAB in sonicated cream has been reported to have beneficial effects on atopic dermatitis in human skin (Di Marzio et al., 2003). Given the importance of understanding the basic mechanism of the apparently beneficial action of pediococci in the intestinal barrier, the reported activity in this work represents great potential to benefit human health. However, more detailed mechanistic research would be necessary for its practical implementation.

The hydrolysis of PL by PLase also has potential use in the food industry, specifically in egg yolk for manufacture of mayonnaise, in refinement of vegetable oils, and in baking and cheese making (De Maria et al., 2007; Borrelli and Trono, 2015). The baking industry can potentially substitute PLase for emulsifiers, because natural emulsifiers can be produced from the PL and lipid hydrolysis in the dough, improving softness and increasing loaf volume in bread. This stabilizing effects of hydrolysis products are due to the interactions between protein and gas bubbles in the dough (Gerits et al., 2014). Phospholipases in the dairy industry during yogurt, ice cream, and cheese production may increase production yield without affecting quality. Specifically in cheese, between 85 and $95 \%$ of milk fat and $75 \%$ of milk proteins are retained in the cheese curd; the rest is in the whey and brine. Using PLase enzymes before renneting can increase cheese yield through fat retention (Lilbæk et al., 2006).

\section{ACKNOWLEDGMENTS}

García-Cano is supported by the postdoctoral fellowship provided by the Mexican National Council for Science and Technology (CONACyT, Mexico City; number 208631). This study was funded by the Parker Endowment at The Ohio State University (Columbus; grant number 00100). The authors have not stated any conflicts of interest.

\section{REFERENCES}

Annous, B. A., M. F. Kozempel, and M. J. Kurantz. 1999. Changes in membrane fatty acid composition of Pediococcus sp strain NRRL B-2354 in response to growth conditions and its effect on thermal resistance. Appl. Environ. Microbiol. 65:2857-2862. https://doi .org/10.1128/AEM.65.7.2857-2862.1999.

Barbosa, J., S. Borges, and P. Teixeira. 2015. Pediococcus acidilactici as a potential probiotic to be used in food industry. Int. J. Food Sci. Technol. 50:1151-1157. https://doi.org/10.1111/ijfs.12768.

Borrelli, G. M., and D. Trono. 2015. Recombinant lipases and phospholipases and their use as biocatalysts for industrial applications. Int. J. Mol. Sci. 16:20774-20840. https://doi.org/10.3390/ ijms160920774.

Bose, A., and H. Keharia. 2013. Production, characterization and applications of organic solvent tolerant lipase by Pseudomonas aeruginosa AAU2. Biocatal. Agric. Biotechnol. 2:255-266. https://doi .org/10.1016/j.bcab.2013.03.009.

Carlin, M. R., S. K. Kazemi, N. Sangwan, and R. D. J. Cano. 2018. Probiotics and methods of use. The Biocollective LLC, assignee. US Pat. 62/594,201.

Chen, S., and P. V. Subbaiah. 2007. Phospholipid and fatty acid specificity of endothelial lipase: Potential role of the enzyme in the delivery of docosahexaenoic acid (DHA) to tissues. Biochim. Biophys. Acta 1771:1319-1328. https://doi.org/10.1016/j.bbalip.2007 .08 .001 .

Chich, J.-F., K. Marchesseau, and J.-C. Gripon. 1997. Intracellular esterase from Lactococcus lactis ssp. lactis NCDO 763: Purification and characterization. Int. Dairy J. 7:169-174. https://doi.org/10 .1016/S0958-6946(97)00001-0.

Chikindas, M. L., M. J. Garciagarcera, A. J. M. Driessen, A. M. Ledeboer, J. Nissenmeyer, I. F. Nes, T. Abee, W. N. Konings, and G. Venema. 1993. Pediocin PA-1, a bacteriocin from Pediococcusacidilactici PAC1.0, forms hydrophilic pores in the cytoplasmic membrane of target-cells. Appl. Environ. Microbiol. 59:3577-3584 https://doi.org/10.1128/AEM.59.11.3577-3584.1993.

Cohen, J. C. 2003. Endothelial lipase: Direct evidence for a role in HDL metabolism. J. Clin. Invest. 111:318-321. https://doi.org/10 .1172/JCI200317744.

Davender, R., P. Attri, J. Singh, A. K. Puniya, and S. Dhanda. 2012. SDS-PAGE analysis of membrane and extracellular proteins of vancomycin-resistant Pediococcus acidilactici. Ann. Biol. 28:9-11.

De Maria, L., J. Vind, K. M. Oxenbøll, A. Svendsen, and S. Patkar. 2007. Phospholipases and their industrial applications. Appl. Microbiol. Biotechnol. 74:290-300. https://doi.org/10.1007/s00253 -006-0775-x.

Di Marzio, L. D., C. Centi, B. Cinque, S. Masci, M. Giuliani, A. Arcieri, L. Zicari, C. De Simone, and M. G. Cifone. 2003. Effect of the lactic acid bacterium Streptococcus thermophilus on stratum corneum ceramide levels and signs and symptoms of atopic dermatitis patients. Exp. Dermatol. 12:615-620. https://doi.org/10 .1034/j.1600-0625.2003.00051.x.

Dippe, M., and R. Ulbrich-Hofmann. 2009. Spectrophotometric determination of phosphatidic acid via iron(III) complexation for assaying phospholipase D activity. Anal. Biochem. 392:169-173. https: /doi.org/10.1016/j.ab.2009.05.048.

Dubey, V., A. K. Mishra, A. R. Ghosh, and B. K. Mandal. 2019. Probiotic Pediococcus pentosaceus GS4 shields brush border mem- 
brane and alleviates liver toxicity imposed by chronic cadmium exposure in Swiss albino mice. J. Appl. Microbiol. 126:1233-1244. https://doi.org/10.1111/jam.14195.

Eko Sukohidayat, N. H., M. Zarei, B. S. Baharin, and M. Y. Manap. 2018. Purification and characterization of lipase produced by Leuconostoc mesenteroides ssp. mesenteroides ATCC 8293 using an aqueous two-phase system (ATPS) composed of Triton X-100 and maltitol. Molecules 23:1800. https://doi.org/10.3390/ molecules23071800.

El Soda, M. E., H. Abd El Wahab, N. Ezzat, M. J. Desmazeaud, and A. Ismail. 1986. The esterolytic and lipolytic activities of the lactobacilli. II. Detection of the esterase system of Lactobacillus helveticus, Lactobacillus bulgaricus. Lactobacillus lactis and Lactobacillus acidophilus. Lait 66:431-443. https://doi.org/10.1051/lait: 1986428.

Esteban-Torres, M., J. M. Mancheño, B. de las Rivas, and R. Muñoz. 2014. Production and characterization of a tributyrin esterase from Lactobacillus plantarum suitable for cheese lipolysis. J. Dairy Sci. 97:6737-6744. https://doi.org/10.3168/jds.2014-8234.

Ferrè, F., and P. Clote. 2006. DiANNA 1.1: An extension of the DiANNA web server for ternary cysteine classification. Nucleic Acids Res. 34(Suppl 2):W182-W185. https://doi.org/10.1093/nar/ gkl189.

Flores-Díaz, M., L. Monturiol-Gross, C. Naylor, A. Alape-Girón, and A. Flieger. 2016. Bacterial sphingomyelinases and phospholipases as virulence factors. Microbiol. Mol. Biol. Rev. 80:597-628. https:/ /doi.org/10.1128/MMBR.00082-15.

Fuquay, J. W., P. F. Fox, and P. L. H. McSweeney. 2011. Encyclopedia of Dairy Sciences. 2nd ed. Academic Press, Cambridge, MA.

García-Cano, I., M. Campos-Gómez, M. Contreras-Cruz, C. E. Serrano-Maldonado, A. González-Canto, C. Peña-Montes, R. Rodríguez-Sanoja, S. Sánchez, and A. Farrés. 2015. Expression, purification, and characterization of a bifunctional 99-kDa peptidoglycan hydrolase from Pediococcus acidilactici ATCC 8042. Appl. Microbiol. Biotechnol. 99:8563-8573. https://doi.org/10.1007/s00253 -015-6593-2.

García-Cano, I., D. Rocha-Mendoza, J. Ortega-Anaya, K. Wang, E. Kosmerl, and R. Jiménez-Flores. 2019. Lactic acid bacteria isolated from dairy products as potential producers of lipolytic, proteolytic and antibacterial proteins. Appl. Microbiol. Biotechnol. 103:5243-5257. https://doi.org/10.1007/s00253-019-09844-6.

Gerits, L. R., B. Pareyt, K. Decamps, and J. A. Delcour. 2014. Lipases and their functionality in the production of wheat-based food systems. Compr. Rev. Food Sci. Food Saf. 13:978-989. https://doi .org/10.1111/1541-4337.12085.

Gunstone, F. D., J. L. Harwood, and F. B. Padley. 1994. The Lipid Handbook. 2nd ed. CRC Press, Boca Raton, FL.

Hernández, I., M. de Renobales, M. Virto, F. J. Pérez-Elortondo, L. J. R. Barron, C. Flanagan, and M. Albisu. 2005. Assessment of industrial lipases for flavour development in commercial Idiazabal (ewe's raw milk) cheese. Enzyme Microb. Technol. 36:870-879. https://doi.org/10.1016/j.enzmictec.2004.12.032.

Holland, R., and T. Coolbear. 1996. Purification of tributyrin esterase from Lactococcus lactis ssp. cremoris E8. J. Dairy Res. 63:131-140. https://doi.org/10.1017/S0022029900031605.

Holland, R., S.-Q. Liu, V. L. Crow, M.-L. Delabre, M. Lubbers, M. Bennett, and G. Norris. 2005. Esterases of lactic acid bacteria and cheese flavour: Milk fat hydrolysis, alcoholysis and esterification. Int. Dairy J. 15:711-718. https://doi.org/10.1016/j.idairyj.2004.09 .012 .

Hopfner, K.-P., A. Karcher, L. Craig, T. T. Woo, J. P. Carney, and J. A. Tainer. 2001. Structural biochemistry and interaction architecture of the DNA double-strand break repair Mre11 nuclease and Rad50-ATPase. Cell 105:473-485. https://doi.org/10.1016/S0092 $-8674(01) 00335-\mathrm{X}$

Javed, S., F. Azeem, S. Hussain, I. Rasul, M. H. Siddique, M. Riaz, M. Afzal, A. Kouser, and H. Nadeem. 2018. Bacterial lipases: A review on purification and characterization. Prog. Biophys. Mol. Biol. 132:23-34. https://doi.org/10.1016/j.pbiomolbio.2017.07 .014 .
Kakariari, E., M. D. Georgalaki, G. Kalantzopoulos, and E. Tsakalidou. 2000. Purification and characterization of an intracellular esterase from Propionibacterium freudenreichii ssp. freudenreichii ITG 14. Lait 80:491-501. https://doi.org/10.1051/lait:2000140.

Kaur, R., and S. K. Tiwari. 2018. Membrane-acting bacteriocin purified from a soil isolate Pediococcus pentosaceus LB44 shows broad host-range. Biochem. Biophys. Res. Commun. 498:810-816. https: //doi.org/10.1016/j.bbrc.2018.03.062.

Kris-Etherton, P. M., and J. A. Fleming. 2015. Emerging nutrition science on fatty acids and cardiovascular disease: Nutritionists perspectives. Adv. Nutr. 6:326S-337S. https://doi.org/10.3945/an .114 .006981 .

Landete, J. M., and J. L. Arqués. 2017. Fluorescent lactic acid bacteria and bifidobacteria as vehicles of DNA microbial biosensors. Int. J. Mol. Sci. 18:1728. https://doi.org/10.3390/ijms18081728.

Lilbæk, H. M., M. L. Broe, E. Høier, T. M. Fatum, R. Ipsen, and N. K. Sørensen. 2006. Improving the yield of Mozzarella cheese by phospholipase treatment of milk. J. Dairy Sci. 89:4114-4125. https:// doi.org/10.3168/jds.S0022-0302(06)72457-2.

Lopes, M. de F. S., A. L. Leitão, M. Regalla, J. J. F. Marques, M. J. T. Carrondo, and M. T. B. Crespo. 2002. Characterization of a highly thermostable extracellular lipase from Lactobacillus plantarum. Int. J. Food Microbiol. 76:107-115. https://doi.org/10.1016/ S0168-1605(02)00013-2.

Marilley, L., and M. G. Casey. 2004. Flavours of cheese products: Metabolic pathways, analytical tools and identification of producing strains. Int. J. Food Microbiol. 90:139-159. https://doi.org/10 .1016/S0168-1605(03)00304-0.

McSweeney, P. L. H., and M. J. Sousa. 2000. Biochemical pathways for the production of flavour compounds in cheeses during ripening: A review. Lait 80:293-324. https://doi.org/10.1051/lait:2000127.

Miller, D. J., L. Shuvalova, E. Evdokimova, A. Savchenko, A. F. Yakunin, and W. F. Anderson. 2007. Structural and biochemical characterization of a novel Mn2+-dependent phosphodiesterase encoded by the $y f c E$ gene. Protein Sci. 16:1338-1348. https://doi .org/10.1110/ps.072764907.

Murru, E., S. Banni, and G. Carta. 2013. Nutritional properties of dietary omega-3-enriched phospholipids. BioMed Res. Int. 2013:965417. https://doi.org/10.1155/2013/965417.

Nishizuka, Y. 1992. Intracellular signaling by hydrolysis of phospholipids and activation of protein kinase C. Science 258:607-614. https: //doi.org/10.1126/science.1411571.

Peña-Montes, C., M.E. Mondragón-Tintor, J.A. Castro-Rodríguez, I. Bustos-Jaimes, A. Navarro-Ocaña, and A. Farrés. 2013. Immobilization and biochemical properties of the enantioselective recombinant NStcI esterase of Aspergillus nidulans. Enzyme Res. 2013:928913. https://doi.org/10.1155/2013/928913.

Pezzilli, R. 2009. Chronic pancreatitis: Maldigestion, intestinal ecology and intestinal inflammation. World J. Gastroenterol. 15:16731676. https://doi.org/10.3748/wjg.15.1673.

Rahman, R. N. Z. A., S. N. Baharum, A. B. Salleh, and M. Basri. 2006. S5 lipase: An organic solvent tolerant enzyme. J. Microbiol. 44:583-590.

Rodriguez, A. V., M. D. Baigorí, S. Alvarez, G. R. Castro, and G. Oliver. 2001. Phosphatidylinositol-specific phospholipase C activity in Lactobacillus rhamnosus with capacity to translocate. FEMS Microbiol. Lett. 204:33-38. https://doi.org/10.1111/j.1574-6968 2001.tb10858.x.

Roussel, A., S. Canaan, M.-P. Egloff, M. Rivière, L. Dupuis, R. Verger, and C. Cambillau. 1999. Crystal structure of human gastric lipase and model of lysosomal acid lipase, two lipolytic enzymes of medical interest. J. Biol. Chem. 274:16995-17002. https://doi.org/10 .1074/jbc.274.24.16995.

Settanni, L., and G. Moschetti. 2010. Non-starter lactic acid bacteria used to improve cheese quality and provide health benefits. Food Microbiol. 27:691-697. https://doi.org/10.1016/j.fm.2010.05.023.

Shi, D., L. Lv, D. Fang, W. Wu, C. Hu, L. Xu, Y. Chen, J. Guo, X. Hu, A. Li, F. Guo, J. Ye, Y. Li, D. Andayani, and L. Li. 2017. Administration of Lactobacillus salivarius LI01 or Pediococcus pentosaceus LI05 prevents CCl4-induced liver cirrhosis by protecting 
the intestinal barrier in rats. Sci. Rep. 7:6927. https://doi.org/10 1038/s41598-017-07091-1.

Songer, J. G. 1997. Bacterial phospholipases and their role in virulence. Trends Microbiol. 5:156-161. https://doi.org/10.1016/ S0966-842X(97)01005-6.

Svendsen, A., K. Borch, M. Barfoed, T.B. Nielsen, E. Gormsen, and S.A. Patkar. 1995. Biochemical properties of cloned lipases from the Pseudomonas family. Biochim. Biophys. Acta BBALipids Lipid Metab. 1259:9-17. https://doi.org/10.1016/0005 -2760(95)00117-U

Thierry, A., Y. F. Collins, M. C. Abeijón Mukdsi, P. L. H. McSweeney, M. G. Wilkinson, and H. E. Spinnler. 2017. Lipolysis and metabolism of fatty acids in cheese. Chapter 17 in Cheese. Chemistry, Physics and Microbiology. 4th ed. P. L. H. McSweeney, P. F. Fox, P. D. Cotter, and D. W. Everett, ed. Academic Press, San Diego, CA.

Tokumura, A. 2011. Physiological significance of lysophospholipids that act on the lumen side of mammalian lower digestive tracts. J. Health Sci. 57:115-128. https://doi.org/10.1248/jhs.57.115.

Tsakalidou, E., and G. Kalantzopoulos. 1992. Purification and partial characterization of an esterase from Lactococcus lactis ssp lactis strain ACA-DC 127. Lait 72:533-543. https://doi.org/10.1051/ lait:1992638.

Van Hoorde, K., M. Heyndrickx, P. Vandamme, and G. Huys. 2010. Influence of pasteurization, brining conditions and production en- vironment on the microbiota of artisan Gouda-type cheeses. Food Microbiol. 27:425-433. https://doi.org/10.1016/j.fm.2009.12.001.

Wan, Y., C. Liu, and Q. Ma. 2019. Structural analysis of a Vibrio phospholipase reveals an unusual Ser-His-chloride catalytic triad. J. Biol. Chem. 294:11391-11401. https://doi.org/10.1074/jbc RA119.008280.

Williams, R. S., G. Moncalian, J. S. Williams, Y. Yamada, O. Limbo, D. S. Shin, L. M. Groocock, D. Cahill, C. Hitomi, G. Guenther, D. Moiani, J. P. Carney, P. Russell, and J. A. Tainer. 2008. Mre11 dimers coordinate DNA end bridging and nuclease processing in double-strand-break repair. Cell 135:97-109. https://doi.org/10 .1016/j.cell.2008.08.017.

Zhang, Y., Y. Cheng, G. H. Hansen, L. L. Niels-Christiansen, F. Koentgen, L. Ohlsson, Å. Nilsson, and R. D. Duan. 2011. Crucial role of alkaline sphingomyelinase in sphingomyelin digestion: A study on enzyme knockout mice. J. Lipid Res. 52:771-781. https:/ /doi.org/10.1194/jlr.M012880.

\section{ORCIDS}

Erica Kosmerl @ https://orcid.org/0000-0002-0751-4990

Rafael Jiménez-Flores @ https://orcid.org/0000-0003-4905-5021 